\title{
Trans-humanismo e Budismo: O passado e futuro superando o sofrimento
}

\author{
Transhumanism and Buddhism: Past and Future overcoming suffering
}

Diego da Silva Pereira ${ }^{1}$

\begin{abstract}
Resumo
O objetivo desse artigo é tratar de conceitos do Trans-humanismo e alguns conceitos do budismo; apresentar possíveis relações, com ênfase nos conceitos de "Visão Correta", Impermanência e Sofrimento, tentando compreender quão relacionados e entrelaçados estão estes temas. Para tanto, há a necessidade de uma explicação mais clara sobre o desenvolvimento do movimento trans-humanista e as tecnologias aplicadas a partir do mesmo. Além disso, faremos uma breve introdução ao budismo e aos conceitos que utilizaremos nessa abordagem. Para chegarmos ao nosso objetivo, a partir de uma análise bibliográfica, pretende-se discutir o quanto os conceitos da filosofia trans-humanista se comunicam com alguns conceitos budistas, no que se refere principalmente à superação do sofrimento humano.
\end{abstract}

Palavras - Chaves: Trans-humanismo, Futurismo, Budismo, Impermanência, Sofrimento.

\begin{abstract}
This paper aims to discuss about transhumanism concept and buddhism, making posible relations, with enphasis on the "Right View" Impermanence and Suffering concepts, trying to understand what are the bounds in these themes. To make this possible, we need to explain more clearily the development of the trans-humanism activity and the apliable technologies. Furthermore we will do a buddhism introduction and his concepts. Start from the bibliographic analysis, is intended to discuss how the concepts of transhumanist philosophy communicate with some buddhist concepts, focusing on superation of human suffer.
\end{abstract}

Keywords: Transhumanism, Futurism, Buddhism, Impermanence, Suffering.

\section{Trans-humanismo: Novos humanos}

Observamos, com o passar dos anos, fortes avanços tecnológicos e científicos na humanidade. Fato é que a ciência se multiplicou exponencialmente no último século. Quando falamos de tecnologia, costumeiramente tendemos a relacionar somente a computadores e a peças eletrônicas. Acabamos por esquecer os avanços em tecnologia aplicada, ou seja, a

\footnotetext{
${ }^{1}$ Graduado em Teologia pela Universidade Metodista de São Paulo (UMESP). Possui interesse nas áreas de mitologias, religiões clássicas, orientais e futurismo. Atualmente é bolsista da CNPQ, cursando o Mestrado em Ciência da Religião pela Universidade Federal de Juiz de Fora -MG. Contato: diegus@rocketmail.com
} 
tecnologia na prática diária, que são essenciais para a medicina, por exemplo. Esquecemos que a tecnologia, seja ela primitiva ou não, é o que faz a humanidade se desenvolver. A tecnologia está em tudo: em descobertas médicas e farmacêuticas; nos sistemas que tornam as cidades mais seguras, o transporte mais rápido, entre outros benefícios na infraestrutura, que favorecem a todos. São aparatos que facilitam a vida cotidiana e abrem espaço para comunicação imediata, colocando os humanos em contato com grupos próximos ou distantes. Tudo isto através das tecnologias aplicadas e práticas (More, 2017, pp. 6-12). Fato é que tais tecnologias abarcam toda a filosofia trans-humanista, em que os melhoramentos no corpo humano podem ser feitos com a aplicação direta de aparatos tecnológicos.

O termo trans-humanismo apareceu pela primeira vez em 1957, apresentado pelo geneticista Julian Sorell Huxley, no livro: Novas garrafas para novos vinhos. Os transhumanistas encontraram nos avanços tecnológicos a confirmação de suas profecias: a tecnologia poderia libertar o ser humano das perdas naturais, da velhice e doenças. Até quem sabe, uma busca por imortalidade. Os progressos das ciências e tecnologias trazem, sem dúvida, melhoras na qualidade da vida e nos tornam cada vez mais longevos. Vários cientistas se uniram à causa Tans-humanista, propagando o tema de maneira expansiva dentro da comunidade científica. O filósofo e cientista político Max More foi o primeiro a aprimorar e transformar o conceito do trans-humanismo em uma filosofia em seu ensaio: Transhumanismo: para uma filosofia futurista (More, 1990, pp. 6-12). More acabou por fundar o primeiro instituto de Criogenia da Inglaterra nos anos 70. Foi um dos primeiros a introduzir na comunidade científica uma filosofia que visava falar do pós-humano. Outro expoente dentro do universo trans-humanista é o professor da Universidade de Oxford, Nick Bostrom, o fundador da Associação Mundial Trans-humanista e escritor do livro Superintelligence, que fala sobre as estratégias, caminhos na evolução que o trans-humanismo pode trazer para a humanidade.

Reduzindo o conceito, o trans-humanismo visa o melhoramento das capacidades físicas e mentais através da tecnologia. Em termos gerais, é a visão de que a condição humana não é imutável e que pode e deve ser questionada a todo instante. Aplicada a isto, a tecnologia é usada para a superação dos limites humanos. O trans-humanismo é uma maneira de pensar sobre o futuro que se baseia na premissa de que a espécie humana, na condição atual, não é o estágio final de nosso desenvolvimento. É uma filosofia que procura a contínua aceleração da evolução da vida inteligente, além das limitações humanas por meio da ciência e da tecnologia (Brandão, 2016, pp. 127-134). 
É importante notar que a maioria das diferenças entre nossas vidas e a vida de nossos antepassados estão, em última instância, ligadas à tecnologia, especialmente se entendermos a palavra em seu sentido mais amplo, para incluir não só aparelhos e máquinas, mas também técnicas, processos e instituições. Neste sentido, podemos dizer que a tecnologia é a soma total de informações transmissíveis e culturalmente úteis (Bostrom, 2009, pp. 186-216). A linguagem é uma tecnologia neste sentido, juntamente com tratores, armas de fogo, algoritmos de classificação e quaisquer outras informações, que reunidas, geram um resultado.

Existem poucos recursos mais úteis do que a capacidade cognitiva, que é responsável pelo processo de aquisição do conhecimento. Fato é que precisamos de uma melhor cognição para buscarmos equilíbrio em uma sociedade cada vez mais complexa, na qual as informações ficam mais disponíveis e nossas ações têm mais consequências de longo alcance. O processo de tomada de decisões tem sido cada vez mais importante. $\mathrm{O}$ aprimoramento cognitivo se faz mais necessário para que se possa compreender e interagir bem com o mundo ao redor. Esse aprimoramento pode ser definido como a amplificação ou extensão das capacidades fundamentais da mente, ou seja, a melhora ou aumento na capacidade de processar as informações. A cognição pode ser definida como um processo que usamos para organizar a informação, através de: aquisição de informação (percepção), seleção (atenção), representação (compreensão) e retenção (memória) de informações. E só então, usamos para orientar o comportamento (raciocínio e coordenação). O trans-humanismo visa melhorar e expandir estes processos do cérebro humano, tudo isto com tecnologia aplicada na fisiologia humana (Sandberg; Bostrom 2006, pp. 201-227).

Mas quais seriam estas tecnologias?

Uma extensa gama de tecnologias são atualmente usadas em vários métodos de desenvolvimento. Entre tantas, algumas específicas se fazem mais essenciais na visão transhumanista, são elas: a biotecnologia, a nanotecnologia e a tecnologia da informação (Bostrom, 2009, pp. 186-216). Biotecnologia é o conjunto de conhecimentos que permite a utilização de agentes biológicos (organismos, células, organelas, moléculas) para obter bens ou assegurar serviços. A Engenharia Genética ocupa um lugar de destaque como tecnologia inovadora, seja porque permite substituir métodos tradicionais de produção (Hormônio de Crescimento, Insulina), ou porque permite obter produtos inteiramente novos (Organismos transgênicos). Este campo se faz necessário para o trans-humanismo devido às pesquisas genéticas e possíveis modificações e melhoramentos de genes humanos. 
Nanotecnologia é um termo usado para referir-se ao estudo de manipulação da matéria numa escala atômica e molecular, ou seja, é a ciência e tecnologia que foca nas propriedades especiais dos materiais de tamanho nanométricos, ou seja, que são invisíveis a olho nu. $\mathrm{O}$ principal objetivo é criar novos materiais, novos produtos e processos a partir da capacidade moderna de ver e manipular átomos e moléculas. A nanotecnologia é muito presente nas pesquisas básicas de neurociência. Nanodotas fluorescentes são pontos luminosos utilizados na pesquisa de neurociências, que permitem a observação direta da ação de cada organismo dentro do cérebro. A nanotecnologia é um facilitador da pesquisa de neurociência relevante para o aprimoramento cognitivo. Outra aplicação que temos são os medicamentos ou hormônios em formato de microchips ou nanoestruturas que são instalados no corpo humano e fazem liberação controlada das substâncias desejadas. Cientistas acreditam que isto poderia até mesmo levar a um caminho para a terapia genética (Sandberg; Bostrom, 2006, pp. 20142015). A nanotecnologia traz muitos avanços para circuitos e peça de eletrônicas, podendo assim executar várias melhorias físicas no corpo humano, de acordo com o conceito transhumanista.

A Tecnologia da Informação é o conjunto de todas as atividades e soluções providas por recursos de computação que visam a produção, o armazenamento, a transmissão, o acesso, a segurança e o uso das informações. Atualmente usamos vários recursos para organizar as informações que chegam até nós. Recursos externos, naturalmente, já são usados para o aprimoramento cognitivo, seja caneta e papel ou software de computador, como organizadores pessoais. Não existe praticamente nenhum conhecimento cognitivo sem amplificação de hardware ${ }^{2}$ ou software sexterno. $^{3}$

$\mathrm{O}$ trans-humanismo visa alcançar um ponto em que componentes externos ajam em conjunto com o corpo e que expandam ainda mais a nossa capacidade cognitiva, além dos recursos que já temos. Através desses hardwares ou softwares, poderíamos nos conectar a melhoramentos em nosso cérebro. Poderíamos gerar melhoramentos em nossa visão, capacidade de reconhecimento facial avançado, melhorar nossa memória entre outras inúmeras possibilidades. Com implantes neurais seria possível se conectar a computadores, descarregar e manipular as informações recebidas durante o cotidiano. Seria a criação de uma super-memória, que sem dúvidas, traria perigos e incertezas por estarem localizadas fora de

\footnotetext{
${ }^{2}$ Peça ou componente físico que tem um propósito ou função específica, seja uma caneta, uma peça de computador ou algum componente mecânico.

${ }^{3}$ Conjunto de instruções a serem seguidas ou executadas na manipulação, recepção ou modificação de um dado ou informação. Os pensamentos podem ser considerados softwares, assim como programas de computador.
} 
nossa mente. Talvez seria o fim dos pensamentos privados (Sandberg; Bostrom, 2006, pp.

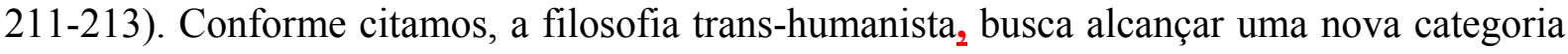
de vivência, em que seríamos "pós-humanos". O termo "pós-humano" tem sido usado em sentidos diferentes por vários autores. A sua significação se enquadra mais no sentido que propõe características e saberes além dos seres humanos. Pode-se entender que o "póshumano" é um ser que tenha pelo menos uma capacidade, aumentada ou gerada através de tecnologia, que seja além dos humanos convencionais.

\section{Ensinamentos de Buda: alguns conceitos budistas}

O budismo é uma filosofia ou religião não-teísta, com base nos ensinamentos de Buda em que não existe a ideia de Deidade. É uma das três principais religiões do mundo, juntamente com o cristianismo e o islamismo, e pode ser considerada uma das mais antigas. Teve seu começo a cerca de 2.500 anos A.E.C (antes da era comum) na Índia, onde os monges vagavam levando os ensinamentos, iniciando um dos maiores movimentos missionários da história religiosa mundial. Na era moderna, o budismo começou a construir uma presença significativa nas Américas e Europa entre as populações imigrantes e locais, transformando-a em uma religião com alcance verdadeiramente global (Buswell, 2004, pp. VII).

Em suma, é uma estratégia pedagógica que busca alcançar a superação do sofrimento através de uma série de práticas. Uma das iniciais é a prática da "visão correta". Que é a maneira correta, segundo o budismo, de se enxergar a verdadeira realidade e a natureza dos fenômenos. Buda, ao ser questionado pelo professor indiano Kaccāyana sobre a noção de "visão correta", responde:

O mundo, Kaccāyana, geralmente se inclina em direção a duas perspectivas: existência e não existência. Para aquele que percebe na perspectiva correta o surgimento do mundo como ele vem-a-ser, a noção de não existência do mundo não ocorre. Para aquele que percebe corretamente a destruição do mundo como ele vem-a-ser, a noção de existência não ocorre... 'tudo existe': isso é um extremo, Kaccāyana; 'nada existe': Kaccāyana, este é o segundo extremo. Sem se aproximar de nenhum desses extremos, o Tathāgatha lhe ensina a doutrina do meio. ${ }^{4}$ (Buda apud Andrade, 2015, p. 36)

\footnotetext{
${ }^{4}$ No original, em Páli: "Dvayanissito khvāyam, kaccāna, loko yebhuyyena - atthitañceva natthitañca. Lokasamudayam kho, kaccāna, yathābhūtạ̣ sammappaññāya passato yā loke natthitā sā na hoti. Lokanirodhaṃ kho, kaccāna, yathābhūtaṃ sammappaññāya passato yā loke atthitā sā na hoti. Sabbaṃ atthī'ti kho, kaccāna, ayameko anto. 'Sabbam natthī'ti ayaṃ dutiyo anto. Ete te, kaccāna, ubho ante anupagamma majjhena tathāgato dhammaṃ deseti” SN II.17.
} 
É necessário entender que o budismo explicita o caminho do meio como uma estratégia de vivência e ponderamento. Como Buda disse "Tudo existe" e "Nada existe". Essa noção de realidades e fenômenos é muito trabalhada no budismo. O meio entre o "um" e a total "não-existência" seria o "zero", que é um número muito expressivo para os transhumanistas. O zero é o marco inicial de um novo momento. Muitos projetos tecnológicos contém a expressão "Marco Zero", pois esta expressão denota o início de algo inovador.

A realidade é questionada a todo instante no universo budista. Somos frutos de nexos causais e temos por tendência criar etiquetas linguísticas para aquilo que acreditamos ser nossa realidade. A realidade, entretanto, está muito além do que enxergamos. A "visão correta" (em sânscrito, samyag-dṛști) não é simplesmente um tipo de análise ou avaliação do real; no budismo, ela serve como questionadora de ações. Ora, só agimos de determinadas maneiras, pois acreditamos que existem maneiras certas de fazer determinada coisa (Andrade, 2015, p. 192). A criação de realidades parece ser algo inerente a nós, seres humanos.

O conceito de impermanência (em sânscrito, anitya), também é muito trabalhado na ótica budista. O budismo primitivo tratou o problema da impermanência de uma maneira muito racional, segundo o qual a impermanência é um fato inegável da existência humana a partir do qual nada que pertence a esta terra seja fixo:

A impermanência é, portanto, uma característica de todos os seres condicionados, quer dos grandes sistemas cósmicos ou dos sistemas microscópicos. Galáxias, planetas, humanidade, seres, átomos, partículas subatômicas: nenhum desses escapa da transitoriedade, da mudança. (Andrade, 2015, p. 169)

Assim, o Budismo declara que, neste mundo, não há nada que seja fixo e permanente. Buda declarou: "Tudo está sujeito a alterações e mais alterações” e seus seguidores aceitaram que a existência era um fluxo e um contínuo seguimento. De acordo com os ensinamentos do Buda: a vida é comparável a um rio. É um momento progressivo, uma sucessiva série de momentos diferentes, unindo-se para dar a impressão de um fluxo contínuo. Ele muda de causa para causa, efeito para efeito, um ponto para outro, um estado de existência para outro, dando uma impressão externa de que é um movimento contínuo e unificado, onde, na realidade, não é. O rio de ontem não é o mesmo que o rio de hoje. O rio deste momento não 
será o mesmo que o rio do próximo momento. A vida também. Muda continuamente, torna-se algo ou outro de momento a momento.

Mesmo sob um ponto de vista biológico, isso é verdade. Sabemos que as divisões celulares ocorrem continuamente em cada ser vivo. As células velhas em nossos corpos morrem e cedem continuamente aos novos que estão se formando. Como as ondas no mar, a cada momento, surgem e morrem vários pensamentos em cada indivíduo. Psicologicamente e fisicamente ele nunca é o mesmo todo o tempo. Tecnicamente falando, nenhum indivíduo é sempre composto da mesma quantidade de energia. Somos material mental e material celular o tempo todo. Estamos sujeitos às mudanças e a mudança é um movimento contínuo.

Impermanência, conforme mencionamos nos parágrafos acima é algo contínuo e dinâmico que está presente em nossa realidade, seja ela criada ou não. Afinal o conceito de realidade no universo budista está relacionado com a visão correta, que faz o indivíduo enxergar os fatos sobre outro viés: aquele que é verdadeiro, segundo a tradição.

Segundo o budismo, o sofrimento (em páli, Dukkha) é uma característica básica de toda a vida neste mundo. É a primeira das quatro Nobres Verdades ensinadas por Buda. Embora mais frequentemente traduzido como "Sofrimento", a palavra original no idioma páli engloba uma ampla variedade de coisas que causam dor. Aparece sob inúmeros significados em textos budistas como: nascimento, velhice, doença e morte; como tristeza, sofrimento mental e físico; agitação entre outros. O desapego é uma forma de evitar o sofrimento, pois como já mencionado, não existe uma existência permanente no mundo. Se uma pessoa se apega a coisas cuja a natureza é impermanente, com a esperança de que essas coisas permaneçam estáveis e imutáveis, então essa pessoa irá sofrer continuamente quando confrontado com a mudança inevitável. De acordo com os ensinamentos budistas, o sofrimento é uma característica inescapável de toda a vida e não pode ser aliviado, exceto através da iluminação (Buswell, 2004, p. 192).

\section{Nirvana Tecnológico: Uma iluminação elétrica?}

Com os devidos conceitos de trans-humanismo e Budismo abarcados, podemos estabelecer uma série de paralelos.

Conforme tratamos, o conceito de "visão correta" no budismo diz respeito a ótica em que enxergamos a realidade. A realidade que é insubstancial, mas insistimos em instrumentalizar com etiquetas linguísticas. A visão correta seria entender a verdadeira noção de realidade, em que tudo é insubstancial. Este conceito é muito tratado no trans-humanismo, 
visto que, com a tecnologia e suas aplicações, seríamos receptores de melhoramentos. Teríamos acesso a criação de inúmeras realidades e talvez assim conseguíssemos criar algo insubstancial, por mais paradoxo que pareça. Isso poderia ser possível através da tecnologia de realidade virtual: um ambiente simulado em que os sentidos humanos perceberão aquilo que forem programados para sentir. Melhoramentos neurais em conjunto com tais realidades, talvez possam nos dar a possibilidade de viajarmos até o conceito da não substância, por assim dizer, uma viagem transcendental. Com implantes neurais e melhoramentos na cognição, os trans-humanistas enumeram possibilidades infindas de se adentrar em novos mundos e universos simulados até mesmo sem interfaces mecânicas. Tudo isto através de tecnologia implantada diretamente no corpo humano. ${ }^{5}$ Máquinas dotadas e munidas da mais alta tecnologia passam a tomar conta cada vez mais de nosso cotidiano, onde a força motriz humana alimenta uma rede de inovações tecnológicas e faz com que caminhemos para um marco não muito distante: a singularidade tecnológica. Este evento será um divisor na evolução humana, visto que é neste momento que a inteligência artificial (construída por tecnologias), superará a inteligência humana. Especialistas acreditam que a evolução humana acontece por estágios. O principal seria o quinto estágio: a Fusão de Tecnologia Humana com Inteligência Humana. Isso resultará da fusão do nosso vasto conhecimento humano com a capacidade, velocidade e o compartilhamento de informações. Esse quinto estágio, irá permitir que nossa civilização homem-máquina transcenda as limitações do cérebro humano e nos permitirá superar problemas humanos antigos e amplificar a criatividade humana. Haverá preservação e melhora da inteligência que a evolução nos conferiu ao superar as limitações de evolução biológica. (Kurzweil, 2005, p. sn)

Pautados os pontos sobre as ótica e realidade, surge uma questão: seria paradoxal criar uma realidade dotada de substâncias com o objetivo de torná-la insubstancial? Não seria apenas mais um mero constructo visando algo artificial e superficial?

Fica evidente que os trans-humanistas estão em busca de constante evolução. Palavra essa que parece não exercer um significado finito. A evolução no conceito trans-humanista é constante, gradual e exponencial.

O trans-humanismo é uma classe de filosofias da vida que procuram a continuação e a aceleração da evolução da vida inteligente, além da sua forma atualmente humana e das limitações humanas por meio da ciência e da

\footnotetext{
${ }^{5}$ Disponível em: <http://humanityplus.org/philosophy/transhumanist-faq/\#answer_27>. Último acesso em: 13 de julho de 2017.
} 
tecnologia, guiados por princípios e valores que promovem a vida. (Andrade, 2015, p. 54)

O conceito de Impermanência budista faz, então, uma ponte com o conceito de evolução humana. Se analisarmos sob a ótica de um desenvolvimento tecnológico vemos a gradualidade e o dinamismo cíclico budista aplicado nos conceitos trans-humanistas. Ora, os avanços tecnológicos estão em constante evolução e percebemos isto aplicado em vários melhoramentos no cotidiano. Cada avanço tecnológico em uma época anterior é um trampolim, para que num posterior estágio evolutivo se aprimore ainda mais. A impermanência budista é a capacidade de aceitar alterações em fluxo contínuo. Claro que, tais alterações no contexto trans-humano, são voltados sempre para a evolução da vida humana com exponencial avanço e uso de tecnologia. É impossível dizer até que ponto esse pensamento de evolução tecnológica levará os seres humanos.

Ainda que alguns conceitos budistas e trans-humanistas se comuniquem, existe algo inerente aos seres humanos, segundo Buda: o sofrimento. O budismo pauta alguns processos nos quais nenhum ser humano tem controle e que não se pode mudar. Tais como envelhecer, adoecer e morrer. Nestes pontos, o trans-humanismo caminha em uma direção oposta. As opções de aprimoramento que estão sendo discutidas incluem: a extensão radical da saúde humana e erradicação de doenças com ênfase na eliminação do sofrimento desnecessário (Bostrom, 2003, pp. 493-506). Tudo isto com base em modificações genéticas.

Estar livre de doenças severas seria bom, assim como ter um sistema imunológico mais robusto. Pessoas mais saudáveis podem ser mais felizes. A engenharia genética possui um grande potencial para aliviar o sofrimento humano desnecessário. Para os transhumanistas, enquanto tal aprimoramento genético é adiado, é mais um dia de sofrimento para aqueles que padecem de doenças que poderiam ser evitadas.

Neste sentido, tratamos apenas do sofrimento físico, que é uma redução conceitual, visto que o budismo fala sobre as diversas dores e aflições humanas. No entanto, o budismo sugere que a evasão do sofrimento é possível, mas somente através do Nirvana, que é a iluminação, o conhecimento completo da existência. Vemos:

Renunciantes (śramaṇa/parivrājika) que haviam abandonado tudo enfeitiçados pela promessa do despertar. Este despertar, em seu contexto upanixádico, como vimos, era chamado mokșa. No ambiente budista, nirvāna; este nirvana foi sempre compreendido como o resultado de uma práxis que se deduzia a partir de alguns postulados básicos: a vida que a 
maioria absoluta das criaturas vive é uma vida de profundo sofrimento (duḥkha), angústia e dor; contudo, existe a possibilidade de se escapar deste ciclo recorrente de dor (duḥkhanirodha); para tanto é necessário detectar o fulcro, a origem da dor, o desejo (duhkhasamudāya); finalmente, é determinante abraçar um tipo de vida que permita escapar da dor. (Bostrom, 2003, pp. 493-506)

Nirvana é o termo mais comum usado pelos budistas para descrever um estado de liberdade do sofrimento e é uma das palavras budistas mais conhecidas fora da Ásia. Encontra-se nos dicionários como uma palavra em inglês e já possui um significado de cunho mundial. No entanto, é uma palavra em que os próprios budistas nunca chegaram em acordo, afinal conceituar o que parece ser a meta da tradição se torna complexo.

\section{Conclusão}

Como podemos constatar, ao abordarmos dois temas que parecem fazer parte de um universo tão distante, se faz necessário uma boa dose de analogias e aproximações conceituais. Fato que quando trazemos o trans-humanismo para a questão, temos por tendência promover uma série de conceitos antecipados, de que tal assunto parece somente ser pauta para ficções futuristas e universos distópicos ou irreais. Porém, quando aprofundamos os conceitos e passamos a entender toda a filosofia imbuída na causa trans-humanista, vemos que existe uma comunidade científica com um grande propósito mundial abarcando suas ideias. A composição de toda a filosofia trans-humanista se dá através de uma amálgama de vários campos, envolvendo tecnologias e material humano de várias áreas. Ao que tudo indica, falar de um "pós-humano" atualmente parece algo mais próximo da realidade.

Ao citarmos o budismo e toda a sua tradição, entendemos que uma das principais questões é a superação do sofrimento. Uma meta. Tal esta, que se dará através de uma série de práticas e observações pautadas nas ações. Diferente de superar apenas uma dor ou sofrimento momentâneo, o conceito de salvação budista coloca o Nirvana como o ponto de superação definitiva do sofrimento. Alguns conceitos budistas foram discutidos. O conceito de visão correta faz alusão à realidade que é "real", porém é preciso uma educação do olhar para que se enxergue esta realidade. Também pautamos o conceito de impermanência, que traz à tona um contexto de constante evolução e sujeição a melhorias. O processo que envolve a superação do sofrimento humano é um dos principais pontos que se comunicam com a filosofia trans-humanista, afinal esta parece ser uma meta em comum de ambas as linhas de pensamento. Por um lado a superação do sofrimento e prolongamento da vida humana através 
do uso de tecnologias e estratégias evolutivas parece ser uma realidade não tão distante. Já o Budismo prega que é possível alcançar a superação do sofrimento através de uma série de práticas que a tradição resguarda há mais de 2.000 anos. O passado parece ter ensinado ao futuro como prolongar o presente.

Para escapar do sofrimento, como uma meta, o Nirvana é o ideal budista. Logo, o trans-humanismo, seguindo a mesma dedução... um Nirvana robótico.

\section{Referências Bibliográficas}

ANDRADE, C.B. Budismo e a filosofia indiana antiga. São Paulo: Fonte editorial, 2015.

BRANDÃO, Vera. O Admirável Mundo Novo: O transhumanismo em questão. In: Revista Portal de Divulgação, n.49, Ano VI, Jun. Jul. Ago. 2016, ISSN 2178-3454. Disponível em: $<$ http://www.portaldoenvelhecimento.com/revistanova/index.php/revistaportal/issue/view/56/showToc $>$. Último acesso em: 13 de julho de 2017.

BOSTROM, Nick. Human genetic enhancements: A transhumanist perspective. In: Journal of Value Inquiry, Vol. 37, n. 4, Inglaterra: Oxford University, 2003. p. 493-506. Disponível em: <http://www.nickbostrom.com/ethics/genetic.html>. Último acesso em: $13 \mathrm{de}$ julho de 2017.

BOSTROM, Nick. Why I Want to be a Posthuman When I Grow Up. In: GORDIJIN, Bert. CHADWICK, R. Medical Enhancement and Posthumanity. Oxford: Oxford University, Springer, 2008. Disponível em: <http://www.nickbostrom.com/posthuman.pdf $>$. Último acesso em: 13 de julho de 2017.

BOSTROM, Nick. The Future of Humanity. In: OLSEN, Jan-Kyrre B., SELINGER, E., RIIS, S. (eds). New Waves in Philosophy of Technology. New York: Palgrave McMillan, 2009. p. 186-216. Disponível em: <http://www.nickbostrom.com/papers/future.html $>$. Último acesso em: 13 de julho de 2017.

BUSWELL, Robert E. Encyclopedia of Buddhism. New York: Thomson Gale, 2004. p.192.

KURZWEIL, Ray. The singularity is near: when humans trascend biology. London: Penguim Viking, 2005.

HARVEY, Peter. An introduction to buddhist ethics: Foundations, Values and Issues. Cambridge: University of Sunderland, 2000. Disponível em: <http://www.ereading.club/bookreader.php/142060/An_Introduction_to_Buddhist_Ethics.pdf $>$. Último acesso em: 13 de julho de 2017. 
HUMANITY+ $\quad-\quad$ HUMANITY $\quad+$ Hisponível em: $<$ http://humanityplus.org/philosophy/transhumanist-faq/\#answer_27>. Último acesso em: 13 de julho de 2017.

MORE, Max. Transhumanism: towards a futurist philosophy. In: Extropy 6 (summer), 1990, p. 6-12. Disponível em: <http://fennetic.net/irc/extropy/ext6.pdf>. Último acesso em: 13 de julho de 2017.

ORT - INSTITUTO DE TECNOLOGIA. Disponível em: $<$ http://www.ort.org.br/biotecnologia/o-que-e-biotecnologia/>. Último acesso em: 13 de julho de 2017.

SANDBERG, Anders; BOSTROM, Nick. Converging Cognitive enhancements. In: Annals of New York Academy of Sciences. Nova York: New York Academy of Sciences, 2006. p. 201- 227. Disponível em: <http://www.nickbostrom.com/papers/converging.pdf $>$. Último acesso em: 13 de julho de 2017.

URBANDHARMA - Urban Dharma: Buddhism in America. The Buddhist Concept of Impermanence. Disponível em: <https://www.urbandharma.org/udharma8/imperm.html>. Último acesso em: 13 de julho de 2017. 